\title{
Overcoming the Distance between Friends
}

\author{
Johanna Renny Octavia \\ User System Interaction \\ Elise van den Hoven \\ Department of Industrial Design \\ Eindhoven University of Technology Eindhoven University of Technology \\ Hans De Mondt \\ Den Dolech 2, 5600 MB, Eindhoven, Den Dolech 2, 5600 MB, Eindhoven, \\ The Netherlands \\ The Netherlands \\ Research \& Innovation, ReNA \\ Alcatel-Lucent \\ j.r.octavia@tm.tue.nl \\ e.v.d.hoven@tue.nl \\ Copernicuslaan 50, B-2018, Antwerp, \\ Belgium \\ hans.de_mondt@alcatel-lucent.be
}

\begin{abstract}
Staying in touch is a fundamental aspect in maintaining a longdistance relationship, whether it is in a family context or a friendship. An effective communication appliance can enable families or friends living apart to have a feeling of connectedness and help them to maintain their relationship despite the physical distance. This paper describes the results of an exploration study on people living far away from their families and friends, with a focus on how they stay in touch with their close friends and overcome the distance.

The targeted user group in this study is geographically and physically isolated people. A user study was conducted by means of a survey, focus group and interview. The results show that sharing problems and feelings between two remotely located friends is crucial. Consequently, the design goal was set to enable users to notify and physically comfort each other, in a subtle way, through a remote but shared experience, whenever a problem or feeling occurs.
\end{abstract}

\section{Categories and Subject Descriptors}

H.4.3 [Information Systems Applications]: Communications Applications; H.5.2 [Information Interfaces and Presentation (e.g. HCI)]: User Interfaces - User-centred design

\section{General Terms}

Design.

\section{Keywords}

Communication appliance, awareness, connectedness, longdistance relationship, tangible interaction, personal artefacts.

\section{INTRODUCTION}

Globalization has changed our world in so many different ways. One of the effects is the increasing migration of people from one country to another, which can have various reasons, such as having a new job, studying, or going on holiday. This phenomenon is resulting in a situation where families and friends live far away from one another, physically separated and geographically distributed.

Maintaining a long-distance relationship, whether between

(c) Johanna Renny Octavia, Elise van den Hoven \& Hans De Mondt, 2007

Published by the British Computer Society

Volume 2 Proceedings of the 21st BCS HCI Group Conference

HCI 2007, 3-7 September 2007, Lancaster University, UK Devina Ramduny-Ellis \& Dorothy Rachovides (Editors) family members or friends, faces many challenges. When physical separation occurs, there is a higher risk of relationship deterioration, which in turn may lead to relationship dissolution. Once one's relationship deteriorates, the possibility of losing friends is higher than losing family members. Family ties are for life, where as friends may come and go. Considering this, relationship maintenance between friends seems more challenging than between family members. In this paper, we focus on the exploration of long-distance relationships between close friends.

\section{RELATED WORK}

Technology-mediated communication plays a significant role in facilitating interpersonal communication (e.g. between family members, friends, couples) and group communication (e.g. among co-workers), when face-to-face communication is not viable. Much research has been done to explore how technology-mediated communication can support remotely located people to stay in touch and connected with each other. This form of communication ranges from emails, phones, and instant messaging applications to awareness systems.

Existing network communication technologies facilitate staying in touch with remote families or friends to some extent. Media such as email, instant messaging, and telephone, are considered content-oriented communication, focusing on conveying meaningful information. However, communication activities in daily life and social relationships involve much more than just the exchange of explicit information. Kuwabara [9] et al. proposed the concept of connectedness-oriented communication, which aims to foster a feeling of connectedness to maintain and enhance human social relationships. Liechti and Ichikawa [10] introduced the idea of affective awareness as a general sense of being close to families and friends. These studies support the idea that the communication media that are currently available do not fully support maintaining longdistance relationships.

One way to stay in touch is by means of an awareness system. An awareness system is a new form of technology-mediated communication that has been widely studied over the last decade. An awareness system is defined as a system that facilitates lightweight, emotional, informal forms of communication that help people to effortlessly maintain awareness of each other's whereabouts and activities [8]. If designed effectively, an awareness system provides connectedness and a sense of being close to one's family or friends.

Time-wise there are two types of communication: synchronous communication, then the interaction takes place in real time, and asynchronous communication, in that case the information exchanged is stored and can be accessed later when the receiving party feels the need. 
In this respect awareness systems can be seen as a new type of communication medium that augments existing ones since it offers the possibility of having asynchronous communication before switching to synchronous communication.

Following the concept of connectedness-oriented communication [9], several works on awareness systems have focused in supporting people that are emotionally-close in maintaining their relationship while living physically separated by providing a feeling of connectedness. For example, family members (e.g. ASTRA [11] and Familyware [5]); couples (e.g. Feather and Scent [13] and Lover's Cup [2]); and close friends (e.g. Shaker [13] and FaintPop [9]). Most of these studies focus on staying in touch within a family context. Although some studies also try to cover staying in touch between friends $[9,11,13]$, no study has ever focused completely on friends.

In line with the notion of supporting awareness and enhancing remote communication, there are several applications for awareness systems designed based on the idea of tangible interaction. PSyBench [1] facilitates remote users not only to collaborate in a shared physical workspace but also to have a strong feeling of each other's physical presence. InTouch [1] is designed to enable haptic interpersonal communication between remote users. More recently, Social Radio [4] is presented as a tangible awareness system that enables small intimate groups to stay in touch and mediate a feeling of connectedness among them through sharing personal music. Another example, Keep in Touch [12] enables remote couples to maintain intimacy by means of a fabric touchscreen. Tangible Interaction (TI) is a recent field that has been growing rapidly in the last few years. The idea behind it is that digital information is made accessible to users through everyday physical artefacts in their everyday environment.

Hoven and Eggen [6] presented an extension to the taxonomy of Ullmer and Ishii [14] by adding a category of TI with personal artefacts. Physical artefacts are categorized as personal when the artefact has a personal meaning to the user and most likely the user also owns the artefact. Using personal artefacts rather than generic ones in TI is argued to reduce the learning time for users since they already have a mental model regarding the personal artefact. Existing TI for awareness systems all use generic artefacts $[1,4,12]$

Hoven [7] incorporated the use of personal objects, namely souvenirs, in the design of a Digital Photo Browser, a TI application for supporting recollection of personal memories. It is suggested that using personal objects may give an affordance for users to interact with TI applications in a better way since a mental model already exists concerning the object and the associated digital information.

This paper presents the exploration phase of a study on staying in touch with physically separated friends. The study aims to design a connectedness-oriented communication appliance to support staying in touch and maintaining relationships, by means of tangible interaction and the use of personal artefacts.

\section{EXPLORATION PHASE}

The targeted user group in this study are people who move away from their friends. Being isolated can lead to loneliness and depression [3], which in the end might affect their wellbeing. Establishing contact with other people could alter this situation. Therefore, this group is considered to have a need for communication.
Two categories of isolation are studied. First, geographic isolation caused by a geographical distance, for example moving to a new place for work or study. Second, physical isolation caused by a certain physical condition, such as being in exile, displaced or very ill. In this study, expatriates and international students represent the first group; and asylum seekers represent the second group.

The exploration phase consists of two parts: a general exploration on long-distance relationships and a more focused continuation.

\subsection{Long-Distance Relationship Exploration}

To gather an initial understanding of the research problem, an online survey and a focus group session were carried with questions such as: What do people experience when living far away from their close friends? In what ways do they stay in touch? What kind of difficulties do they face with respect to communication? Does relationship deterioration occur? And what kind of personal artefacts do they have that are linked to their friends?

\subsubsection{Survey}

The online survey was aimed at both people who moved and people who stayed behind. The survey was distributed by snowball sampling via email and mouth-to-mouth advertisement. Valid responses were obtained from 101 participants (73\% moved and $27 \%$ left behind, $59 \%$ female and $41 \%$ male, reason for moving: $52 \%$ study, $25 \%$ work, $15 \%$ follow family and $8 \%$ better living condition). From the survey, the main findings were:

- People who moved and those who are left behind both share similar feelings, such as finding it hard or difficult to be apart, missing the other, feeling distant, sad, and lonely. In addition, no significant differences are found when comparing the two groups on frequency of contact with each other, presence of personal artefacts, and selfproclaimed relationship deterioration.

- The major means of communication is email (92\%), instant messaging (73\%) and phones (68\%).

- The type of information shared remains more or less the same compared to when they were physically close: personal matters (news, problems and feelings), work or study, family, and friends. However, the information is less detailed, they only share updates on old information or news.

- Talking, sharing, being together and doing things together, face-to-face meetings and having physical contact are important elements that a long-distance friendship misses.

- Relationship deterioration is experienced by half of the respondents $(52 \%)$. After living far away for a certain period, they feel not as close as before, have less contact, share less information, and have less common things or shared experiences. The main reasons are that they are busy and living different lives.

- Half of the respondents (50\%) have a personal artefact that relates to their close friend, mainly pictures and presents. They perceive the artefact as personal because it reminds them of how the close friend looks, of their great moments together, and brings back memories.

Knowing that the problems that people experienced, either when they moved away or stayed behind, are more or less 
similar, it was decided to focus on people who moved in the next steps of the study since we have easier access to this group of people.

\subsubsection{Focus Group}

Two focus group sessions were conducted. The first group (geographically-isolated) consisted of 2 males and 2 females; two of them were international students, 1 expatriate, and 1 expatriate's family member. The second group (physicallyisolated) were 3 asylum seekers living in an asylum centre, two of them were male and 1 female. The main purpose of the focus group was to acquire a deeper understanding of the users and their requirements, and also to dive into the survey findings. Three research materials were used in the focus group: an introductory questionnaire, "a day in the life" video of two personas (representing each group), and participants' personal artefacts. Some of the main findings were:

- Time constraints, time difference, living different lives, different life styles, and different life rhythms are the main difficulties in staying in touch with close friends.

- The situation of being away from friends is more difficult for the asylum seekers since it is a permanent situation for them, and also the means of communication available are more limited. They also realize that their relationships are not likely to get weakened, as their close friends tend to have more understanding towards their condition.

- The feeling of envy sometimes hinders sharing experiences between geographically isolated participants with their close friends. However, having shared experiences, or sharing the same experience, is considered to be a very important element in a friendship. When friends no longer have shared experiences, over time they will drift apart. In the end, this may lead to relationship deterioration.

- Memories of prior shared experiences, special attention, something in common, and problems, are the things that make participants feel connected with their close friends.

Findings show that shared experiences turn out to be essential things that people miss in a long-distance friendship, which over time may cause the friendship to deteriorate. Therefore at this point, the research continued with a focus on facilitating a remote shared experience. It was also chosen only to proceed with the first group (expatriates, international students, and their accompanying family members), because these people, as well as their friends, will have easier access to the potential design solution, which will consist of technological equipment that is not readily available to all.

\subsection{Shared Experiences Exploration}

In this study, shared experience is described as the things that two or more close friends do together, not necessarily at the same time, but give them the same experience. Having many shared experiences is like glue that holds a friendship together. The main question raised in this phase is: What kind of experiences did people share when they still lived nearby? What kind of shared experiences would they like to have now even though they live far apart? And how do they manage to have shared experiences now?

\subsubsection{Survey}

Another online survey was carried out, by sending emails to people who participated in the previous survey. For this second survey, 32 people responded ( $78 \%$ female and $22 \%$ male, $50 \%$ study, 34\% work and 16\% follow family). The main findings of the survey were:

- Sharing problems and feelings is the shared experience that most respondents had before and wished to have now. For a top five of shared experiences see Table 1.

Table 1. Top five shared experience that respondents had before and wished to have now

\begin{tabular}{|c|c|c|c|}
\hline \multirow{2}{*}{ No. } & \multirow{2}{*}{ Kind of shared experience } & \multicolumn{2}{|c|}{$\begin{array}{c}\text { \%ospondents } \\
(\mathbf{n = 3 2})\end{array}$} \\
\cline { 3 - 4 } & & Had & Wished \\
\hline 1 & Sharing problems and feelings & $88 \%$ & $78 \%$ \\
\hline 2 & Sharing jokes and funny stories & $84 \%$ & $66 \%$ \\
\hline 3 & Going out for a drink or meal & $81 \%$ & $56 \%$ \\
\hline 4 & Hanging out & $75 \%$ & $50 \%$ \\
\hline 5 & $\begin{array}{c}\text { Having physical contacts } \\
\text { (hugs, shoulder pats) }\end{array}$ & $69 \%$ & $50 \%$ \\
\hline
\end{tabular}

- It is still possible to share problems, feelings, jokes and funny stories to some extent, by talking about them over the phone, chatting, or sharing via emails. For other shared experiences such as going out for a drink or meal and having physical contacts, are not feasible anymore until they visit each other. However, some people prefer making new friends as a remedy.

Even though the survey participants live far away from their close friends, the shared experience they miss most is to share problems and feelings. For that reason, the design in this research will be focusing on facilitating remote shared experience of sharing problems and feelings.

\subsubsection{Interviews}

To acquire more detailed and elaborate information on the experience of sharing problems and feelings, semi-structured interviews were conducted with 5 participants. Four of them were females and one male; three of them were international students, 1 expatriate, and 1 expatriate's family member. The main findings were:

- Knowing a friend's problems and feelings connects people emotionally and builds a stronger friendship. The problems and feelings shared are mainly big, life-related problems and deep, intense feelings that they normally only share with very close friends.

- When people are living near to one another and one has problems, they meet face-to-face, spend time together and talk the problems through. When living far away, synchronous communication (e.g. talking on the phone, chatting) is difficult because of time constraints, different time zones, and the fact that sharing problems requires an enormous amount of energy and time.

- When people are meeting each other, it is also easier to sense whenever their close friend is having a problem or not feeling well (through body language and facial expression). When living far away, sensing each other's current feelings is nearly impossible. Hence, people become less sensitive to the feelings of their close friends.

- People find it difficult to share big problems. They simply do not know how to start expressing their problem. They wish their close friends would instantly know and ask them what is wrong. 
- People miss the physical contact they usually have with their close friends right after sharing their problems, such as hugs or simple comforting touches on the hands or shoulders. They said that sometimes they just wanted to be comforted and did not need to hear any solutions instantly.

\subsection{Design Goals}

This study focuses on designing an appliance to facilitate two close friends in sharing their problems and feelings over a distance. The thorough exploration described in this paper gave us sufficient understanding of the research problem to come up with the following two design goals:

1) People should be able to let their remote friend know that they have a problem or a particular feeling, without using any words, in a subtle way.

2) People should be able to give comfort physically to their remote friend.

\section{CONCLUSIONS AND FUTURE WORK}

We performed an exploration study to investigate how people stay in touch and maintain their long-distance friendships when they are living far away from their close friends. A shared experience is considered very important in a friendship as it brings a feeling of connectedness to one's close friends. Due to the distance, physically separated friends are more likely to have less shared experiences which over time may cause the relationship to deteriorate. Sharing problems and feelings is the shared experience that is highly missed in a long-distance friendship. The comprehensive exploration has led us to an interim conclusion that facilitating a remote experience of sharing problems and feelings between close friends is crucial. Two design goals have been identified: the design should enable users in a non-obtrusive way to notify each other, and physically comfort each other whenever a problem or feeling takes place.

The approach of this study is user-centred design, which means that after the completion of the user and requirements study, the conceptual design phase will take place. Subsequently, the selected design concept will be prototyped and followed by a user evaluation.

\section{ACKNOWLEDGMENTS}

We thank all the dedicated participants in this study and the Ambient Media team at Research \& Innovation, ReNA, AlcatelLucent, in particular Marc Godon and Laurence Claeys, for their valuable contributions.

\section{REFERENCES}

[1] Brave, S., Ishii, H., and Dahley, A. Tangible Interfaces for Remote Collaboration and Communication. In Proceedings of the 1998 ACM Conference on Computer Supported Cooperative Work (CSCW'98) (Seattle, Washington, USA, November 14-18, 1998). ACM Press, 169-178.

[2] Chung, H., Lee, C.J., and Selker, T. Lover's Cups: Drinking Interfaces as New Communication Channels. In Proceedings of the 2006 Conference on Human Factors in Computing Systems (CHI'06) (Montréal, Québec, Canada, April 22-27, 2006). ACM Press, 375-380.

[3] Devito, J. Human Communication. New York, USA: Longman Publishing Group, 1997.
[4] Etter, R. and Röcker, C. A Tangible User Interface for Multi-User Awareness Systems. In: Proceedings of the International Conference on Tangible and Embedded Interaction (TEI '07) (Baton Rouge, Louisiana, USA, Feb15-17, 2007). ACM Press, 11-12.

[5] Go, K., Carroll, J.M., and Imamiya, A. Familyware: Communicating with Someone You Love. In Proceedings of the IFIP TC9 WG9.3 International Conference on Home Oriented Informatics and Telematics (HOIT'00), "IF at Home: Virtual Influences on Everyday Life" (Wolverhampton, UK, June 28-30, 2000). Information, Technology and Society, 125-140.

[6] Hoven, E. A. W. H. van den, and Eggen, B. Tangible Computing in Everyday Life: Extending Current Frameworks for Tangible User Interfaces with Personal Objects. In: P. Markopoulos et al. (Eds.), EUSAI 2004, LNCS 3295, 230-242.

[7] Hoven, E. A. W. H. van den, and Eggen, B. Digital Photo Browsing with Souvenirs. In: M. Rauterberg et al. (Eds.), Human-Computer Interaction-INTERACT'03, IOS Press, 2003, 1000-1003.

[8] IJsselsteijn, W.A., van Baren, J., and van Lanen, F. Staying in Touch: Social Presence and Connectedness through Synchronous and Asynchronous Communication Media. In: C. Stephanidis and J. Jacko (Eds.), HumanComputer Interaction: Theory and Practice (Part II), volume 2 of the Proceedings of HCI International 2003, 924-928.

[9] Kuwabara, K., Watanabe, T., Ohguro, T., Itoh, Y., and Maeda, Y. Connectedness Oriented Communication: Fostering a Sense of Connectedness to Augment Social Relationships. In Proceedings of the 2002 Symposium on Applications and the Internet (SAINT '02) (Nara, Japan, Jan 28-Feb 01, 2002). IEEE Computer Society, 2002, 186193.

[10] Liechti, O. and Ichikawa, T. A Digital Photography Framework Enabling Affective Awareness in Home Communication. Personal Technologies 4 (1), 2000, 6-24.

[11] Markopoulos, P., Romero, N., van Baren, J., IJsselsteijn, W., de Ruyter, B., and Farshchian, B. Keeping in Touch with the Family: Home and Away with the ASTRA Awareness System. In Proceedings of the 2004 Conference on Human Factors in Computing Systems (CHI'04) (Vienna, Austria, April 24-29, 2004). ACM Press, 1351-1354.

[12] Motamedi, N. Keep in Touch: A Tactile-Vision Intimate Interface. In Proceedings of the $1^{\text {st }}$ International Conference on Tangible and Embedded Interaction (TEI'07) (Baton Rouge, Louisiana, USA, February 15-17, 2007). ACM Press, 21-22.

[13] Strong, R. and Gaver, B. Feather, Scent and Shaker: Supporting Simple Intimacy. In Videos, Demos and Short Papers of CSCW '96. Proceedings of the 1996 ACM Conference on Computer Supported Cooperative Work (CSCW '96) (Boston, Massachusetts, USA, November 1620, 1996). ACM Press, 29-30.

[14] Ullmer, B. and Ishii, H. Emerging framework for tangible user interfaces. IBM Systems Journal, 39 (3-4), 2000, 915 931. 